REGULAR ARTICLE

\title{
IN VITRO REGENERATION OF TWO HIGH-YIELDING EGGPLANT (SOLANUM MELONGENA L.) VARIETIES OF BANGLADESH
}

\section{SABINA YESMIN ${ }^{1}$, MST MUSLIMA KHATUN ${ }^{1}$, TANZENA TANNY ${ }^{1}$, ANICA TASNIM PROTITY ${ }^{2}$, MD SALIMULLAH ${ }^{3}$, IFTEKHAR ALAM ${ }^{*}$}

${ }^{1}$ Plant Biotechnology Division, ${ }^{2}$ Microbial Biotechnology Division, ${ }^{3}$ Molecular Biotechnology Division, National Institute of Biotechnology, Ganakbari, Savar, Dhaka 1349, Bangladesh

\begin{abstract}
An in vitro regeneration protocol was developed for two high-yielding eggplant varieties (Solanum melongena L.) namely BARI begun-4 and BARI begun-6. Multiple shoots were regenerated from cotyledonary explants through organogenesis with growth regulators of different combinations and concentrations. The best response towards multiple shoot regeneration was achieved from cotyledon explants on MS media complemented with $1 \mathrm{mg} / \mathrm{l} \mathrm{BAP+0.2} \mathrm{mg/l} \mathrm{IAA} \mathrm{in} \mathrm{both} \mathrm{the} \mathrm{two} \mathrm{varieties} \mathrm{of}$ eggplant. Elongation of shoots was achieved on hormone free MS medium. Regenerated shoots of both the varieties produced active in vitro root system on half strength of MS medium supplemented with $0.2 \mathrm{mg} / \mathrm{l}$ IBA. The in vitro grown plantlets were acclimatized in soil, grew up to maturity, flowered, fruited and produced seeds as normal healthy plant like the control.
\end{abstract}

Keywords: Eggplant, Brinjal cotyledon, In vitro, Organogenesis, Solanum melongena

\section{INTRODUCTION}

Eggplant (Solanum melongena L.) is an economically significant vegetable crop belongs to the Solanaceae family. It is adapted to different ago-climatic zone and cultivated mostly in tropical and temperate regions. There are different varieties of eggplant according to color and shape. Egg-shaped ( $S$. melongena var. esculentum), long and slender shape ( $S$. melongena var. serpentium) and dwarf types (S. melongena var. depressum) are the three main types of eggplants found around the world [1]. Eggplant is an excellent source of vitamins and is also used as a medicine in traditional system [2].

Next to potato, it is the second most important vegetable crop in Bangladesh in terms of total areas in production. It shares about $25 \%$ of our vegetable production areas and to $4.8 \%$ in terms of production weight [3]. Eggplants are mainly cultivated by the small farmers in Bangladesh and are an important source of income for such many resource-constrained farmers. Cultivation of eggplant is essential for their overall economic security. In spite of its huge contribution, eggplant productivity of Bangladesh (7.9 t/ha) lags behind many countries (India 17.4, China 35.9, global average 26.1 t/ha) [4]. Thus, an increased eggplant yield could contribute to more per capita vegetable availability in our country. Insect-pests are one of the major causes of yield loss, in particular, fruit and shoot borer (FSB). Occurrences of abiotic stresses are the other major reason that significantly reduces eggplant production. Large stretches of cultivated land face unfavorable environment with 2 million hectares being prone to tidal surge, 0.75 million hectares to flood and 1.3 million hectares to drought [5]. Therefore, there is an urgent need to improve our crop plants by introducing stress tolerance traits as the gap between the population growth and the food production is enlarging.

Conventional breeding alone is unable to improve this crop. In vitro culture techniques provide an alternative means of propagation and a tool for crop improvement [6]. In the past, tissue culture technique has been used to improve eggplant varieties. But it has not yet been possible to develop abiotic stress tolerant eggplant cultivars using tissue culture method. Under these circumstances, genetic transformation technique can accelerate the development of eggplant varieties. Agrobacterium-mediated genetic transformation is the most widely recognized gene transfer technology for plants.

An efficient and reproducible in vitro regeneration protocol is the pre-requisite of gene transfer technique. Plant regeneration in eggplant is extensively studied via organogenesis and somatic embryogenesis. The important features of in vitro plant regeneration have been studied by many researchers and significant information has been assembled at the cellular and molecular level. There are a number of reports on eggplant regeneration in vitro [2, 723]. Several regeneration protocols of eggplant have been reported earlier. However, it was observed that the

\footnotetext{
Received 19 November 2017; Accepted 10 February 2018

*Corresponding Author

Iftekhar Alam
}

Plant Biotechnology Division, National Institute of Biotechnology, Ganakbari, Savar, Dhaka 1349, Bangladesh

Email: iftekhar@nib.gov.bd

( This article is open access and licensed under the terms of the Creative Commons Attribution License (http://creativecommons.org/licenses/by/4.o/) which permits unrestricted, use, distribution and reproduction in any medium, or format for any purpose, even commercially provided the work is properly cited. Attribution - You must give appropriate credit, provide a link to the license, and indicate if changes were made. 
competency of regeneration depends on various factors like explant type, genotype, maturity and sometimes the same explant show different morphogenetic reaction [12]. Therefore, on the basis of the background described earlier, attempts were made to develop an efficient regeneration protocol suitable for some high yielding eggplant varieties for producing transgenic eggplant by Agrobacterium-mediated genetic transformation.

\section{Materials and methods}

Two varieties of eggplant (Solanum melongena L.), namely BARI begun-4 (Kazla) and BARI begun-6 (ISDoo6) were used in this study. Seeds of two varieties were collected from Bangladesh Agricultural Research Institute (BARI), Joydebpur, Gazipur, Bangladesh.

For germination, the seeds were washed under running tap water for $15 \mathrm{~min}$. Non-viable floating seeds were discarded. The seeds were then soaked in $70 \%$ alcohol for 1 minute and then washed with distilled water. Later, they were surface sterilized in the laminar air flow with $0.1 \% \mathrm{HgCl}_{2}$ for 3-4 min. Then the seeds were washed five times with sterilized distilled water. The surface sterilized seeds were air-dried on a sterilized petri dish containing sterile filter paper. The seeds were then inoculated into conical flask containing $50 \mathrm{ml}$ of agar solidified MS salt [24] with $3 \%$ sucrose for seed germination and seedling development. In each flask 10-12 seeds were inoculated. Cotyledons were collected from 15-17 d old in vitro grown seedlings. Each cotyledon was transversely cut into two-three segments and each segment was used as explant. These explants were then cultured on agar solidified MS supplemented with various concentrations and combinations of BAP, Kn, and IAA for the induction of multiple shoots. The in vitro cultures were maintained in a 16 hour day and 8 hour night photoperiod growth room under fluorescent light at $25 \pm 2{ }^{\circ} \mathrm{C}$ temperature.

Table 1: Individual and combined effect of different concentrations and combinations of BAP, Kin and IAA on multiple shoot regeneration from cotyledon explants of two varieties of eggplant. Data were recorded eight weeks after inculcation of cultures

\begin{tabular}{|c|c|c|c|c|}
\hline $\begin{array}{l}\text { PGR } \\
(\mathrm{mg} / \mathrm{l})\end{array}$ & Variety & $\begin{array}{l}\text { Regeneration frequency } \\
\text { (\%) }\end{array}$ & $\begin{array}{l}\text { Days to initiation of } \\
\text { regeneration }\end{array}$ & $\begin{array}{l}\text { Mean no. of } \\
\text { shoots/explant }\end{array}$ \\
\hline \multicolumn{5}{|l|}{ BAP } \\
\hline \multirow[t]{2}{*}{0.5} & BB-4 & 40.0 & $11-12$ & $2.0 \pm 0.23$ \\
\hline & BB-6 & $43 \cdot 3$ & $12-13$ & $2.26 \pm 0.20$ \\
\hline \multirow[t]{2}{*}{1.0} & BB-4 & 46.0 & $8-10$ & $3.06 \pm 0.35$ \\
\hline & BB-6 & 46.0 & $8-10$ & $3.13 \pm 0.25$ \\
\hline \multirow[t]{2}{*}{1.5} & BB-4 & 50.0 & $11-12$ & $2.46 \pm 0.19$ \\
\hline & BB-6 & 50.0 & $11-12$ & $2.73 \pm 0.26$ \\
\hline \multirow[t]{2}{*}{2.0} & BB-4 & 56.6 & $10-11$ & $3.46 \pm 0.40$ \\
\hline & BB-6 & 53.6 & $10-11$ & $3.53 \pm 0.25$ \\
\hline \multirow[t]{2}{*}{3.0} & BB-4 & 36.0 & $12-13$ & $2.26 \pm 0.22$ \\
\hline & BB-6 & 40.0 & $12-13$ & $2.13 \pm 0.23$ \\
\hline \multicolumn{5}{|l|}{ Kn } \\
\hline \multirow[t]{2}{*}{0.5} & BB-4 & 33.3 & $12-13$ & $1.66 \pm 0.18$ \\
\hline & BB-6 & 30.0 & $12-13$ & $1.73 \pm 0.18$ \\
\hline \multirow[t]{2}{*}{1.0} & BB-4 & 40.0 & $11-12$ & $1.8 \pm 0.2$ \\
\hline & BB-6 & 36.6 & $11-12$ & $1.53 \pm 0.16$ \\
\hline \multirow[t]{2}{*}{1.5} & BB-4 & 43.3 & $12-13$ & $1.93 \pm 0.18$ \\
\hline & BB-6 & 40.0 & $12-13$ & $1.86 \pm 0.16$ \\
\hline \multirow[t]{2}{*}{2.0} & BB-4 & 50.0 & $12-13$ & $2.13 \pm 0.21$ \\
\hline & BB-6 & 43.3 & $12-13$ & $2.4 \pm 0.25$ \\
\hline \multirow[t]{2}{*}{3.0} & BB-4 & 40.0 & $12-13$ & $1.66 \pm 0.21$ \\
\hline & BB-6 & 26.6 & $12-13$ & $1.46 \pm 0.16$ \\
\hline \multicolumn{5}{|c|}{$\mathbf{B A P}+\mathbf{K n}$} \\
\hline \multirow[t]{2}{*}{$1.0+0.5$} & BB-4 & $43 \cdot 3$ & $10-11$ & $2.26 \pm 0.31$ \\
\hline & BB-6 & 43.3 & $10-12$ & $2.13 \pm 0.16$ \\
\hline \multirow[t]{2}{*}{$1.0+1.0$} & BB-4 & 46.6 & $10-11$ & $3.4 \pm 0.34$ \\
\hline & BB-6 & 50.0 & $10-12$ & $3.46 \pm 0.36$ \\
\hline \multirow[t]{2}{*}{$2.0+0.5$} & BB-4 & 50.0 & $9-10$ & $4.33 \pm 0.50$ \\
\hline & BB-6 & $53 \cdot 3$ & $9-10$ & $4.2 \pm 0.36$ \\
\hline \multirow[t]{2}{*}{$2.0+1.0$} & BB-4 & 60.0 & $12-13$ & $2.33 \pm 0.23$ \\
\hline & BB-6 & 56.6 & $12-13$ & $1.93 \pm 0.18$ \\
\hline \multicolumn{5}{|c|}{$\mathbf{B A P}+\mathbf{I A A}$} \\
\hline \multirow[t]{2}{*}{$1.0+0.1$} & BB-4 & $53 \cdot 3$ & $9-10$ & $3.33 \pm 0.23$ \\
\hline & BB-6 & 50.0 & $10-11$ & $3.13 \pm 0.23$ \\
\hline \multirow[t]{2}{*}{$1.0+0.2$} & BB-4 & 73.6 & $10-11$ & $5.33 \pm 0.37$ \\
\hline & BB-6 & 66.6 & $9-10$ & $5.10 \pm 0.29$ \\
\hline \multirow[t]{2}{*}{$2.0+0.1$} & BB-4 & 66.6 & $9-10$ & $3.2 \pm 0.27$ \\
\hline & BB-6 & 63.3 & $9-10$ & $3.0 \pm 0.27$ \\
\hline \multirow[t]{2}{*}{$2.0+0.2$} & BB-4 & 76.6 & $9-10$ & $4.60 \pm 0.30$ \\
\hline & BB-6 & 70.0 & $9-10$ & $4.8 \pm 0.25$ \\
\hline
\end{tabular}


Table 2: Effects of half, full strength MS and IBA on in vitro root induction in regenerated shoots of two varieties of eggplant, data were recorded four weeks after inoculation of cultures

\begin{tabular}{|c|c|c|c|c|}
\hline Media composition & Days to initiate roots & \% of shoots forming roots & $\begin{array}{l}\text { No. of roots/ } \\
\text { shoot }\end{array}$ & Length of roots (cm) \\
\hline \multicolumn{5}{|l|}{ BARI begun-4 } \\
\hline $1 / 2 \mathrm{MS}$ & $8-10$ & 50 & $4.00 \pm 0.26$ & $4.48 \pm 0.18$ \\
\hline MS & $7-8$ & 65 & $4.10 \pm 0.41$ & $4.70 \pm 0.20$ \\
\hline $1 / 2 \mathrm{MS}+0.1 \mathrm{IBA}$ & $8-10$ & 50 & $4.30 \pm 0.30$ & $4.69 \pm 0.31$ \\
\hline $1 / 2 \mathrm{MS}+0.2 \mathrm{IBA}$ & $10-12$ & 69 & $4.50 \pm 0.31$ & $5.05 \pm 0.27$ \\
\hline 1/2 MS+0.5 IBA & $10-12$ & 15 & $2.50 \pm 0.27$ & $2.95 \pm 0.10$ \\
\hline \multicolumn{5}{|l|}{ BARI begun-6 } \\
\hline $1 / 2 \mathrm{MS}$ & $10-11$ & 60 & $3.90 \pm 0.23$ & $4.55 \pm 0.17$ \\
\hline MS & $10-12$ & 65 & $4.20 \pm 0.25$ & $4.67 \pm 0.30$ \\
\hline 1/2 MS+0.1 IBA & $8-10$ & 50 & $4.10 \pm 0.23$ & $4.75 \pm 0.23$ \\
\hline $1 / 2 \mathrm{MS}+0.2 \mathrm{IBA}$ & $10-11$ & 70 & $4.40 \pm 0.22$ & $5.10 \pm 0.28$ \\
\hline 1/2 MS+0.5 IBA & $7-8$ & 10 & $2.30 \pm 0.21$ & $2.76 \pm 0.14$ \\
\hline
\end{tabular}

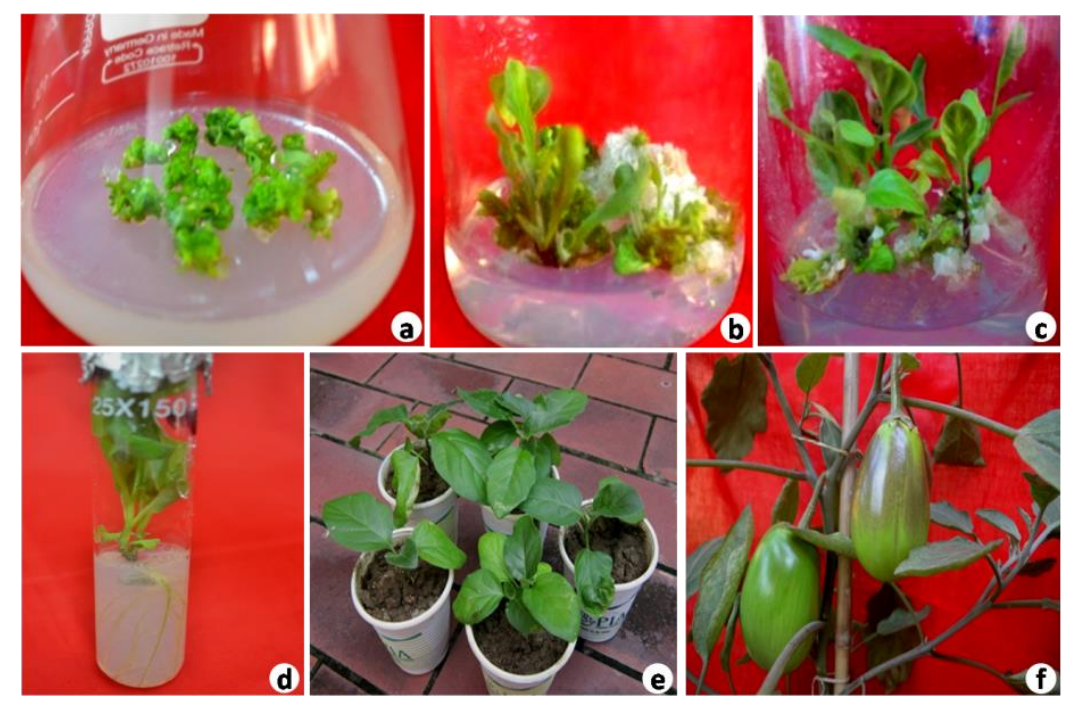

Fig. 1(a-f): In vitro regeneration of eggplant from cotyledon explants. a. Initiation of regeneration; $b$. Induction of multiple shoots on MS+1.0 mg/l BAP+0.2 mg/l IAA after three weeks of culture; c. Development and multiplication of shoots; d. Rooting of in vitro regenerated shoots on half MS $+0.2 \mathrm{mg} / 1 \mathrm{IBA}$; $\mathrm{e}$. Acclimatization of in vitro grown plantlet in a small plastic pot containing soil; f. Fruits developed on regenerated plantlet of BARI begun-6

For root induction, in vitro regenerated shoots $(3.0-4.0 \mathrm{~cm}$ long) were excised and transferred to rooting media. Half or full strength MS media supplemented with different concentrations (0.1-0.5 mg/l) of IBA were used for rooting. After sufficient development of root system plantlets were acclimatized as described previously [25-26]. Briefly, plantlets were transferred to small plastic pots containing mixture of soil and compost (1:2). All pots maintained inside the growth room covered with perforated polythene bags for two to three weeks. After three weeks of acclimatization in the growth room, plantlets were transferred to field for further growth and development.

\section{RESULTS AND DISCUSSION}

In present study, cotyledons were used as explants. Cotyledon explants of two varieties of eggplant were cultured on MS medium supplemented with various concentrations of either BAP or $\mathrm{Kn}$ alone and different concentrations and combinations of BAP, $\mathrm{Kn}$ and IAA combined for multiple shoot regeneration. Table-1 represents the result of the treatments of diverse blends and groupings of growth regulators supplemented with MS towards multiple shoot induction from the cotyledonary explants of the two varieties. It was observed that either BAP or $\mathrm{Kn}$ alone has the positive effect towards multiple shoot regeneration, which coincides the earlier findings [20, 27]. However, of the two cytokinins BAP showed better response in terms of number of shoots per explant in both varieties of eggplant. Among the different concentrations of BAP the maximum number shoot producing explants $(56.66 \%$ and $53.63 \%)$ and highest shoot per explant $(3.46 \pm 0.40$ and $3.53 \pm 0.25$ ) were obtained in $2.0 \mathrm{mg} / \mathrm{l}$ BAP depending on the variety. Results of the present investigation indicate that the number of shoots increased with the gradually increased concentration of BAP up to $(0.5-2.0 \mathrm{mg} / \mathrm{l})$ and decreased with higher concentrations $(3.0 \mathrm{mg} / \mathrm{l})$. Higher concentration of BAP delivered few shoots demonstrating the diminishing regeneration efficiency. Similar findings were obtained earlier in some other eggplant varieties [15, 19, 20, 22, 27]. In present studies $\mathrm{Kn}$ showed less response in terms of number of responsive explants and shoots per explants. This is similar with the results obtained by Sarker et al. [20], Shivaraj and Rao [21] and Pawar et al. [28] using cotyledon explant. 
MS medium supplemented with various concentrations and mixes of BAP and $\mathrm{Kn}$ were used to examine the combined effect on initiation of multiple shoots and their development. No remarkable variation was observed between the two varieties regarding shoot bud initiation and regeneration on a particular medium and hormonal combination. Results of this experiment have been presented in table 1. MS medium augmented with $2.0 \mathrm{mg} / \mathrm{l}$ BAP and $0.5 \mathrm{mg} / \mathrm{l} \mathrm{Kn}$ was found to be most suitable for multiple shoot formation of eggplant variety BARI Begun4 and BARI Begun-6. The highest percentage of shoot producing explants (50\% and 53.33\%), the maximum number of shoot bud induction and shoot multiplication (4.33 \pm 0.50 and $4.2 \pm 0.36)$ were found in this medium for the variety BARI Begun -4 and BARI Begun- 6 respectively. In the present investigation it was observed that during the shoot formation vigorous callus was also produced simultaneously. Moreover, a notable vitrification of shoots was observed under this culture conditions and even on medium with increased agar content (9-10\%) than normal solid medium. Combined effects of two cytokinins were also used by earlier researchers $[14,20]$.

MS medium with various concentrations and combinations of cytokinin and auxin showed variation in the percentage of responsive explants, inductions of shoot bud and proliferation of shoot multiplications (fig. a-b). Among the different concentrations and combinations of BAP and IAA, MS medium along with $1.0 \mathrm{mg} / \mathrm{l} \mathrm{BAP}$ and $0.2 \mathrm{mg} / \mathrm{l}$ IAA was found to be most suitable for multiple shoot formation of eggplant variety BARI Begun-4 and BARI Begun- 6 . The highest percentage of shoot producing explants (73.66\% and 66.66\%) and maximum number of shoot multiplication $(5.33 \pm 0.37$ and $5.10 \pm 0.29)$ were found in this medium for the eggplant variety BARI Begun- 4 and BARI Begun- 6 respectively. In the present investigation, it was observed that to control the basal callusing, small shoots and shoot buds should be subcultured on the same regeneration medium for 7-10 d subsequently two to three weeks of culture initiation and after $10 \mathrm{~d}$ explants with elongating shoots, small shoots and shoot buds should be transferred on hormone free MS medium (fig. c). The elongated and proliferated shoots were separated and the small shoot buds were maintained in the MS basal medium for further elongation. Kamat and Rao [7] reported shoot regeneration from hypocotyl explant of eggplant in presence of BAP and IAA.

Rooting is the vital part for getting complete plantlets from in vitro shoots. Various tests were done to incite roots at the base of excised shoots for both the varieties. In some cases, roots were formed along with shoots in the same regeneration medium but they were not strong enough for transplantation. Therefore, adequate root generation is necessary [29]. For the induction of roots, about 2.0-3.0 $\mathrm{cm}$ long shoots were excised and transferred to both half and full-strength of MS medium without growth regulator and supplemented with different concentrations of IBA. The highest percentage $(70 \%)$ of root formation was recorded within three weeks of inoculation on half MS+0.2 IBA medium (table 2, fig. d). Bhat et al. mentioned 0.5 $\mathrm{mg} / \mathrm{l}$ IBA showed maximum rooting in eggplant [22]. On the other hand, Mallaya et al. [30] reported $1 \mathrm{mg} / \mathrm{l}$ IBA was best for root induction in Arka Shirish variety of eggplant [30]. After adequate root development, plantlets were transplanted into small plastic pots containing soil (fig. e). Following proper acclimatization plantlets were transferred to larger pots and 90\% plants were survived. The survived plants became mature, gave flowers and healthy fruits with viable seeds (fig. f). From the above findings it could be concluded that in the present study, an efficient and reproducible in vitro regeneration protocol has been developed for two varieties of Solanum melongena $L$. from cotyledon explant. This regeneration protocol could be applicable for the genetic transformation of eggplant and other means of crop improvement such as selection of somaclonal variants.

\section{ACKNOWLEDGEMENT}

This work was supported by a grant under the "Special Allocation for Science and Technology", Ministry of Science and Technology, Government of Bangladesh.

\section{REFERENCES}

1. Rajam MV. Polyamines. In: Prasad M. N. V. (ed.), Plant Ecophysiology. John Wiley and Sons Inc., New York1997;343-374.

2. Mir KA, Dhatt AS, Sandhu JS, Sidhu AS. Effect of genotype, explant and culture medium on organogenesis in brinjal. Indian Journal of Horticulture. 2011;68:332-335.

3. BBS. Yearbook of Agricultural Statistics of Bangladesh, $19^{\text {th }}$ edition, Bangladesh Bureau of statistics, Ministry of planning, Government of the People's Republic of Bangladesh. July, 2007.

4. FAOSTAT data. Statistical database of Food and Agriculture Ooganization of the United Nations (online) 2005;URL: http://faostat. fao. org/site/339/default. aspx accessed: July, 14, 2014.

5. World Bank. Bangladesh integrated Agricultural productivity Project, World Bank, June 2011.

6. Anisuzzaman M, Sharmin SA, Mondal SC, Sultana R, Khalekuzzaman M, Alam I, Alam MF. In vitro microrhizome induction in Curcuma zedoaria (Christm.) Roscoe-a conservation prioritized medicinal plant. Journal of Biological Sciences. 2008;8:1216-20.

7. Kamat MG, Rao TS. Vegetative multiplication of eggplants (Solanum melongena L.) using tissue culture techniques. Plant Sciences Letters. 1978;13:57-65.

8. Gleddie S, Keller W, Setterfield G. Somatic embryogenesis and plant regeneration from leaf explants and cell suspensions of Solanum melongena (eggplant). Canadian Journal of Botany. 1983;61:656-666.

9. Rao PVL, Singh B. Plantlet regeneration from encapsulated somatic embryos of hybrid Solanum melongena L. Plant Cell Reports. 1991;10:7-11.

10. Magioli C, Rocha APM, Oliveira, DE, Mansur E. Efficient shoot organogenesis of eggplant (Solanum melongena L.) induced by thidiazuron. Plant Cell Reports 1998;17:661-663.

11. Mukherjee SK, Rathinasabapathi B, Gupta N. Low sugar and osmotic requirements for shoot regeneration from leaf pieces of Solanum melongena L. Plant Cell, Tissue and Organ Culture. 1991;25:13-16.

12. Sharma P, Rajam MV. Genotype, explant and position effects on organogenesis and somatic embryogenesis in eggplant (Solanum melongena L.). Journal of Experimental Botany. 1995;46:135-141.

13. Fari M, Nagy I, Csanyi M, Mityko J, Anderasfalvy A. Agrobacterium-mediated genetic transformation and plant regeneration via organogenesis and somatic embryogenesis from cotyledon leaves in eggplant (Solanum melongena L. cv. Kecskemeti Lila. Plant Cell Reports. 1995;15:82-86.

14. Franklin G, Sheeba C, SitaL. Regeneration of eggplant (Solanum melongena L.) from root explants. In vitro 
Cellular and Devevelopmental Biology-Plant. 2004;40:188-191.

15. Zayova E, Ivanova RV, Kraptchev B, Stoeva D. Indirect shoot organogenesis of eggplant (Solanum melongena L.). Journal of Central European Agriculture. 2012;13:446-457.

16. Tarre E, Magioli C, Margis PM, Sachetto MG, Mansur $\mathrm{E}$, Santiago Farnandes LDR. In vitro somatic embryogenesis and adventitious root initiation has common origin in eggplant (Solanum melongena L.). Revista Brasileira de Botânica. 2004;27:79-84.

17. Huda AKMN, Bari MA, Rahman M, Nahar N. Somatic embryogenesis of two varieties of eggplant (Solanum melongena L.). Research Journal of Botany. 2007;2:195-201.

18. Swamynathan B, Nadanakunjidam S, Ramamourti A, Sindhu K, Ramamoorthy D. In vitro Plantlet Regeneration through Somatic Embryogenesis in Solanum melongena (Thengaithittu Variety). Academic Journal of Plant Sciences. 2010;3:64-70.

19. Kaur M, Dhatt AS, Sandhu JS, Sidhu AS, Gosal SS. Effect of media composition and explant type on the regeneration of eggplant (Solanum melongena L.). African Journal of Biotechnology. 2013;12:860-866.

20. Sarkar RH, Yesmin S, Hoque MI. Multiple shoot formation in Eggplant (Solanum melongena L). Plant Tissue Culture and Biotechnology. 2006;16:53-61.

21. Muktadir MA,Muhammad, Habib MA, Mian MAK, Akhond MAY. Regeneration efficiency based on genotype, culture condition and growth regulators of eggplant (Solanum melongena L.). Agriculture and Natural Resources 2016;50:38-42.

22. Bhat SV, Jadhav AS, Pawar BD, Kale AA, Chimote VP, Pawar SV. In vitro shoot organogenesis and plantlet regeneration in Brinjal (Solanum melongena L.). The Bioscan 2013;8: 821-824.
23. Dobariya KL, Kachhadiya JR. Role of genotype, explant, and culture medium on in vitro morphogenesis in brinjal (Solanum melongena L.). Orissa Journal of Horticulture 2004;32:52-54

24. Murashige $\mathrm{T}$ and Skoog F. A revised medium for rapid growth and bio-assays with tobacco tissue culture. Plant Physiology 1962;15:473-497.

25. Sharmin SA, Alam MJ, Sheikh MM, Zaman R, Khalekuzzaman M, Mondal SC, Haque MA, Alam MF, Alam I. Micropropagation and antimicrobial activity of Curcuma aromatica Salisb., a threatened aromatic medicinal plant. Turkish Journal of Biology. 2013;37:698-708.

26. Sharmin SA, Alam M, Sheikh M, Islam M, Sarker KK, Khalekuzzaman M, Haque M, Alam MF, Alam I. Somatic embryogenesis and plant regeneration in Wedelia calendulacea Less. an endangered medicinal plant. Brazilian Archives of Biology and Technology. 2014;57:394-401.

27. Shivraj G and Rao S. Rapid and efficient regeneration of eggplant (Solanum melongena L). Indian Journal of Biotechnology. 2011;10:125-129.

28. Pawar BD, Jadhav AS, Kale AA, Chimote VP, Pawar SV. In vitro plant regeneration in brinjal (Solanum melongena L.) using cotyledon, hypocotyl and root explants. Vegetos, 2013;26:312-317.

29. Anisuzzaman M, Jarin S, Naher K, Akhtar MM, Alam MJ, Khalekuzzaman M, Alam I, Alam MF. Callus induced organogenesis in okra (Abelmoschus esculents L. Moench.). Asian Journal of Plant Sciences. 2008;7:677-681.

30. Mallaya NP, Ravishankar GA. In vitro propagation and genetic fidelity study of plant regenerated from inverted hypocotyl explants of eggplant (Solanum melongena L.) cv. Arka Shirish. 3 Biotech, 2013;3:4552. 